\title{
Polyurethane Foams Derived from Vegetable Oil Used in the Adsorption of Polychlorinated Biphenyls Present in Insulating Mineral Oil
}

\author{
Marcio Antonio Ferreira Camargo', Antonia Marli dos Santos², Gilberto Orivaldo Chierice ${ }^{3}$, \\ Salvador Claro Neto $^{3}$, Maria Diva Landgraf ${ }^{3}$ \\ ${ }^{1}$ Academic Unit of Passos, University of State of Minas Gerais, Belo Horizonte, Brazil \\ ${ }^{2}$ University Julio of Mesquita Filho, UNESP/IB, São Paulo, Brazil \\ ${ }^{3}$ Institute of Chemistry of São Carlos, University of São Paulo, São Paulo, Brazil \\ Email: mcamargo2004@yahoo.com.br, amsantos@rc.unesp.br, cequil@terra.com.br, salvador@iqsc.usp.br, landgraf@iqsc.usp.br
}

How to cite this paper: Camargo, M.A.F., dos Santos, A.M., Chierice, G.O., Neto, S.C. and Landgraf, M.D. (2018) Polyurethane Foams Derived from Vegetable Oil Used in the Adsorption of Polychlorinated Biphenyls Present in Insulating Mineral Oil. Open Access Library Journal, 5: e4945.

https://doi.org/10.4236/oalib.1104945

Received: September 26, 2018

Accepted: October 21, 2018

Published: October 24, 2018

Copyright $\odot 2018$ by authors and Open Access Library Inc.

This work is licensed under the Creative Commons Attribution International License (CC BY 4.0).

http://creativecommons.org/licenses/by/4.0/

\begin{abstract}
PCBs, polychlorinated biphenyls (polychlorinated biphenyls), are the generic names given to the class of organochlorine compounds resulting from the reaction of the biphenyl group with anhydrous chlorine in the presence of a catalyst. They are toxic, persistent, bioaccumulative and pose the risk of causing harm to human health and the environment. Large quantities of PCBs were produced in several countries between 1927 and 1977. In the United States the prohibition occurred in 1977. Due to high toxicity, production and marketing of PCBs have been banned worldwide since 1980. It was carried out at the Chemistry Institute of Sao Carlos-University of Sao Paulo, and developed a procedure for decontamination of mineral insulating oil containing PCBs values above $50 \mathrm{mg} / \mathrm{kg}$. In the procedure, the contaminated oil was passed by percolation in a column containing polyurethane foam derived from vegetable oil, produced by the Laboratory of Analytical Chemistry and Polymer Technology (GQATP), thus obtaining a 55\% reduction in the levels of PCBs.
\end{abstract}

\section{Subject Areas}

Analytical Chemistry, Environmental Chemistry

\section{Keywords}

Polyurethane Foams, PCBs, Insulating Mineral Oil

\section{Introduction}

The term "mineral oils" refers to oils derived directly from natural petroleum, 
thus distinguishing it from other oils of vegetable or animal origin. Insulating mineral oils are obtained by appropriate refining and extraction processes from certain fractions of natural petroleum distillation. In principle they consist exclusively of hydrocarbons and may also contain impurities or traces of special additives [1]. Polychlorinated biphenyls (PCBs) are a family of synthetic chlorinated aromatic hydrocarbons with good thermal and electrical properties. These properties combined with excellent chemical stability have made them useful in numerous commercial applications. It is estimated that due to the large use of PCBs the accumulated world production since 1920 was approximately $1,200,000$ tons. Of this total, about $60 \%$ was used in transformers and capacitors, $15 \%$ for heat transfer fluids and $25 \%$ as additives in the formulation of plasticizers, paints, adhesives and pesticides. However, its chemical stability and resistance to biodegradation have given rise to concerns related to environmental pollution, hygiene and safety at work. It can be estimated that about 40\% (300,000 tons) entered the environment and that much of the rest is still in use, especially in old electro-electronic equipment [2]. The most important and probable routes of contamination of PCBs to the environment are: accident or loss in the handling of PCBs and/or fluids containing PCBs; vaporization of PCB contaminated components; leaks in transformers, capacitors or heat exchangers; leakage of hydraulic fluids containing PCBs; irregular storage of waste containing PCBs or contaminated waste resulting from the incineration of products containing PCBs; industrial effluents and/or sewage discharged into rivers and lakes [2]. Growing concern about the environmental impact of $\mathrm{PCBs}$ has progressively restricted their use since the early 1970s, and use in new plants and equipment was banned by international agreement in 1986. In new equipment, the insulation mineral oil can no longer contain PCBs in its formulation, having to present a certificate of chemical analysis proving its absence. In Brazil there are no records of the production of PCBs, all of which is imported mainly from the United States and Germany. The restrictions for its use were implemented through Inter-ministerial Ordinance 19, dated January 2, 1981. This decree establishes, among other things, a ban on the manufacture, commercialization and use of PCBs throughout Brazil. This decree also establishes that, in old equipment, where PCBs are present in the insulating oil, whenever there is a risk of potential contamination (oil treatment, transformer repairs, etc.), the oil must be analyzed according to the standard ABNT NBR 13882 [3]. If the PCB content exceeds defined limits, measures must be adopted as indicated in ABNT NBR 8371 [4]. The aforementioned ordinance also prohibits the disposal of $\mathrm{PCBs}$ or contaminated products in watercourses, or exposure of equipment containing PCBs in bad weather, in addition to regulating the place of installation of equipment containing PCBs that are still functioning.

\section{Materials and Methods}

\subsection{Samples}

The procedure for insulating mineral oils was performed according to ABNT 
NBR 13882 [3], which uses solvent for dilution in SPE cartridge (Agilent SampliQ Florisil), in the clean-up process, prior to the determination by gas chromatography in detector by electron capture. The procedure predicts that the composition of the PCBs present in the oils used in transformers and capacitors are in concentrations close to those present in PCB standards. Sampling of the insulating mineral oil was performed according to ABNT NBR 8840 [5]. The adsorption of the PCBs present in the insulating mineral oil was performed by percolation in thermostatic glass column (Figure 1) using an MA-184 Marconi ultra thermostatic bath, containing rigid polyurethane foam derived from vegetable oil, with a known mass, pressed in the powder form between two solid foam discs containing two millimeters thick. The PCB contents were measured before and after the elution of $50 \mathrm{~mL}$ of oil by the foam at temperatures of $20^{\circ} \mathrm{C}$, $40^{\circ} \mathrm{C}$ and $60^{\circ} \mathrm{C}$.

\subsection{Reagents and Solutions}

The extraction of PCBs present in insulating mineral oil was performed using a ratio of 1:20 (v/v) oil and $n$-hexane. This dilution of the oil in $n$-hexane facilitated the interaction of the PCBs with the polyurethane foam, increasing the extraction efficiency. Clean-up is an analytical procedure that removes interfering compounds in the determination of specific analytes such as PCBs. A $2.0 \mathrm{~mL}$ volume of oil was eluted by gravity in Florisil ${ }^{\circledR}$ SPE adsorbent cartridge purchased from Agilent Technologies. The eluted fraction was diluted in $\mathrm{n}$-hexane, then injected in triplicate in CG-DCE, through an automated system, thus reducing the possibility of injected volume errors in the quantification of PCBs.

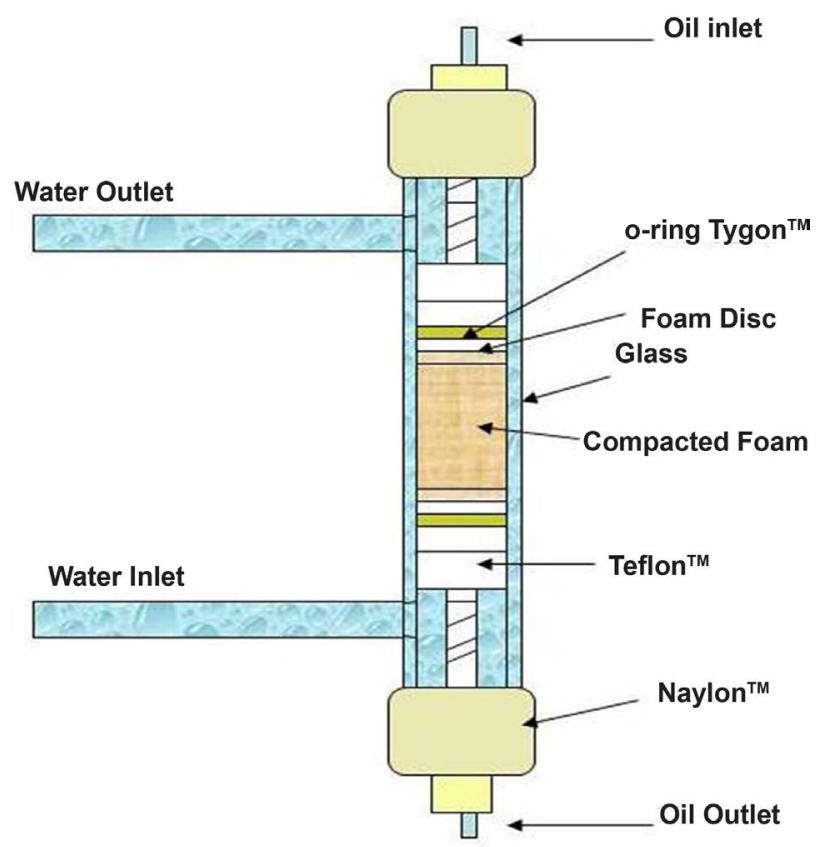

Figure 1. Thermostatic glass column containing rigid polyurethane foam derived from vegetable oil. Source: CAMARGO, Marcio Antonio Ferreira (2010) [12]. 


\subsection{Chromatographic System}

Gas chromatography analyzes were performed on a Shimadzu GC-2010 Chromatograph equipped with electron capture detector (DCE). An RTX5MS capillary column, $30 \mathrm{~m}$ long, $0.25 \mathrm{~mm}$ internal diameter, $0.25 \mu \mathrm{m}$ film thickness, $5 \%$ Diphenyl, 95\% Dimethylpolysiloxane was used. The conditions of the chromatographic analysis method were: Temp.; Column: $170^{\circ} \mathrm{C}\left(1 \mathrm{~min}\right.$.) $5^{\circ} \mathrm{C} / \mathrm{min}$. to $200^{\circ} \mathrm{C}$ (0.0 min.) $10^{\circ} \mathrm{C} / \mathrm{min}$. to $300^{\circ} \mathrm{C}(5 \mathrm{~min})$. Temp.; DCE Detector: $300^{\circ} \mathrm{C}$; Injector: $280^{\circ} \mathrm{C}$; Vol. Injection: $1.5 \mathrm{~mL}$; Pressure: $64.6 \mathrm{Kpa}$; Total Flow: $13.3 \mathrm{~mL} / \mathrm{min}$, Column Flow: $0.94 \mathrm{~mL} / \mathrm{min}$, Purge Flow: $3.0 \mathrm{~mL} / \mathrm{min}$, Split: 1:10, Carrier Gas: $\mathrm{N}_{2}$.

\section{Results and Discussion}

Solutions of the standards of Arocloros 1242, 1254 and 1260 were obtained from Supelco USA. Initially they were prepared separately and then using a mixture of the three standards, as shown in Figure 2.

The analytical curve (Figure 3) was prepared by triplicate injection using a mixture of the three standards in the following concentrations: $1 \mathrm{mg} \cdot \mathrm{kg}^{-1}, 2 \mathrm{mg} \cdot \mathrm{kg}^{-1}$, $2.5 \mathrm{mg} \cdot \mathrm{kg}^{-1}, 4 \mathrm{mg} \cdot \mathrm{kg}^{-1}, 5 \mathrm{mg} \cdot \mathrm{kg}^{-1}$ and $10 \mathrm{mg} \cdot \mathrm{kg}^{-1}$.

The method used in the determination of PCBs in insulating mineral oil was by comparing the total area called the "arochloric region" obtained in the sample, with the total area obtained by the analytical curve. This method has been recommended mainly for the analysis of mineral insulating oil used in transformers [6]. Oils used in transformers have often been analyzed in this way because of the regulations intended to qualify the oils as to their permanence in use or their disposal.

In order to verify the adsorption efficiency of PCBs in polyurethane foam

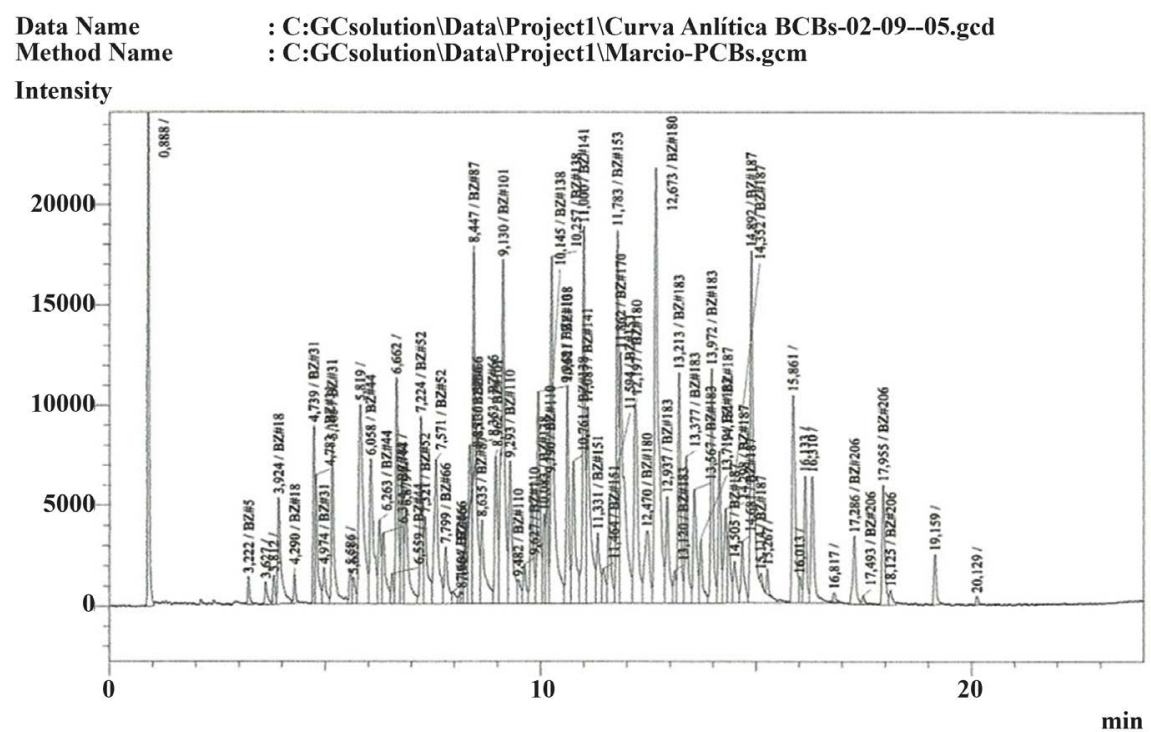

Figure 2. Typical chromatogram of the standard solution mixture of Arocloros 1242, 1254 and 1260. 


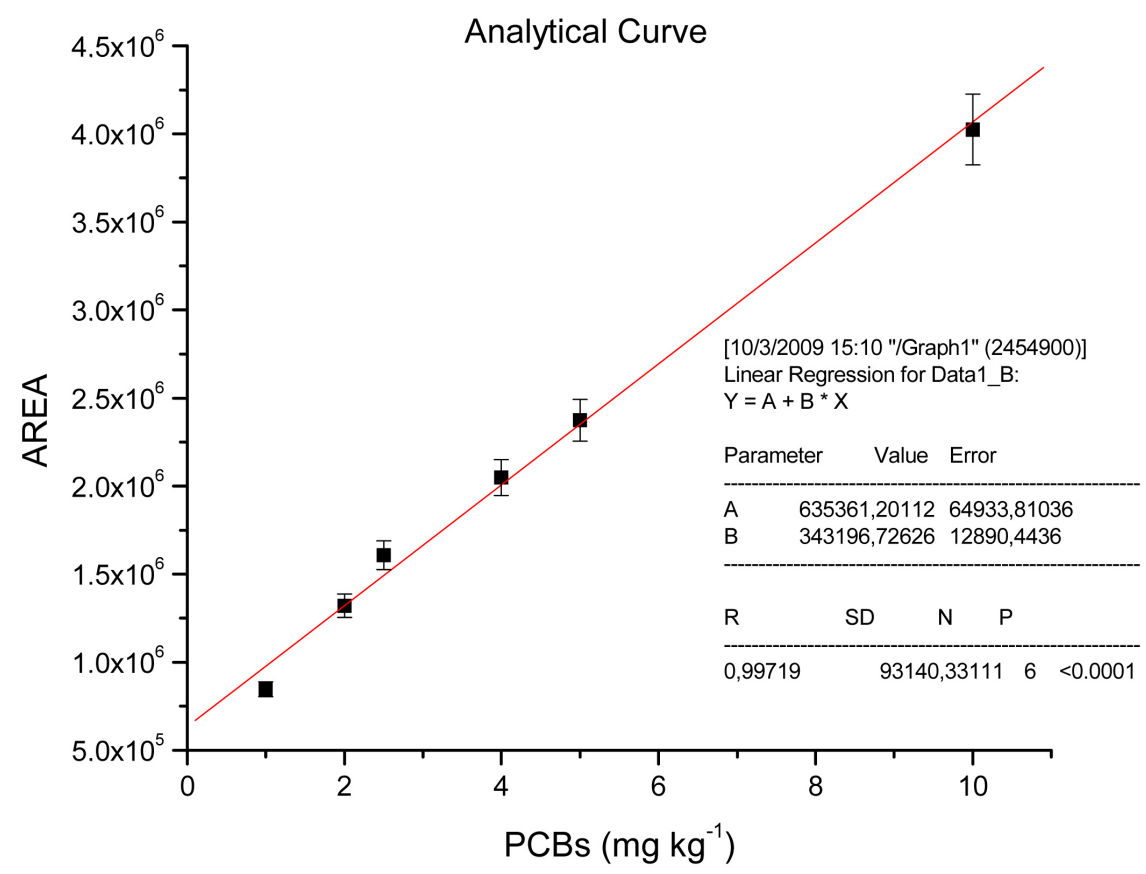

Figure 3. Analytical curve prepared using a mixture of the three standards in the following: concentrations: $1.0 \mathrm{mg} \cdot \mathrm{kg}^{-1}, 2.0 \mathrm{mg} \cdot \mathrm{kg}^{-1}, 2.5 \mathrm{mg} \cdot \mathrm{kg}^{-1}, 4.0 \mathrm{mg} \cdot \mathrm{kg}^{-1}, 5.0 \mathrm{mg} \cdot \mathrm{kg}^{-1}$ and $10.0 \mathrm{mg} \cdot \mathrm{kg}^{-1}$.

derived from vegetable oil, a sample of PCB-free insulation mineral oil was used for saturated column percolation immediately after the elution of a contaminated oil. This oil, free of PCBs, should not show traces of PCBs after passage through the column. As the limits of detection considered were three times the height of the noise, the values obtained for the oil used, about $2.0 \mathrm{mg} \cdot \mathrm{kg}^{-1}$, are within the limit of detection of the method.

Sorption of a compound of a solution into a solid occurs as a result of one of two characteristics in a given system, or the combination of both. The first driving force may be a consequence of the lack of affinity of the compound for the solvent, lipophilicity, while the second is due to the higher affinity of the solute for the solid. In most situations there is a combination of the two forces [7]. The solute establishes bonds with the functional groups of the solid surface by electrostatic, van der Waals or chemical attractions [8]. Therefore, three main types of sorption are distinguished: ion exchange, physical sorption (adsorption) and chemical sorption (absorption).

In order to verify the behavior of the saturation curves determining the non adsorbed quantity after the elutions, three types of foams were used: 1) Functionalized foam containing ammonium polysulfide, 2) Functionalized foam containing thiodiglycol, 3) Non-functionalized foam.

$50 \mathrm{~mL}$ of insulating oil ( $\left.65 \mathrm{mg} \cdot \mathrm{kg}^{-1} \mathrm{PCBs}\right)$ were eluted at $40^{\circ} \mathrm{C}$ through $2.0 \mathrm{~g}$ of ammonium polysulphide-containing functionalized foam, as shown in Figure 4, the non-adsorbed amount of PCBs, and then an aliquot of $2 \mathrm{~mL}$ was separated for further chromatographic analysis. After this procedure all the oil was eluted 


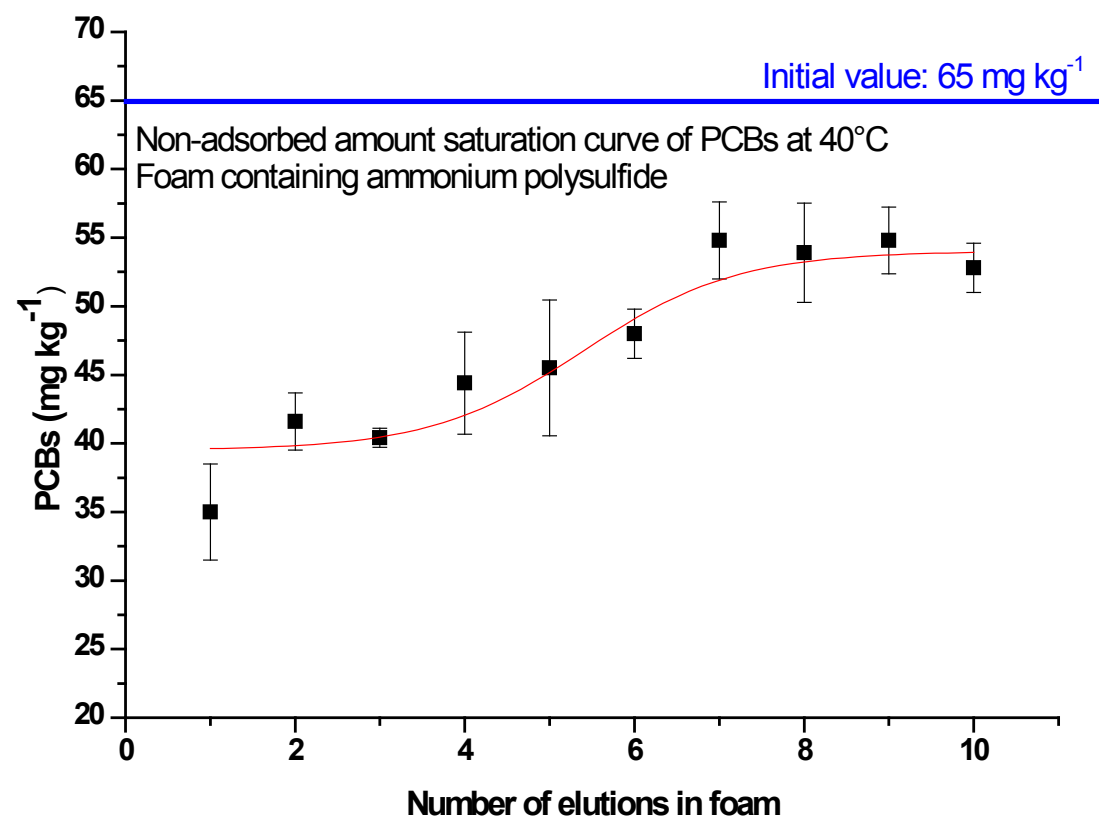

Figure 4. Non-adsorbed amount saturation curve of PCBs at $40^{\circ} \mathrm{C}$ in the foam functionalized with $10 \%$ ammonium polysulfide, after 10 elutions with insulating mineral oil containing $65 \mathrm{mg} \cdot \mathrm{kg}^{-1}$ of PCBs.

again by separating a new aliquot, and so on, until 10 aliquots were obtained.

In Figure 4 the results showed that there was a $24 \%$ reduction in the amount of PCBs after 10 elutions.

$50 \mathrm{~mL}$ of mineral insulating oil (65 mg. $\mathrm{kg}^{-1}$ of PCBs) was eluted at $40^{\circ} \mathrm{C}$ through $2.0 \mathrm{~g}$ of thiodiglycol containing functionalized foam, as shown in Figure 5. A $2 \mathrm{~mL}$ aliquot was then separated for further chromatographic analysis. Thereafter, all the oil was eluted again by separating a new aliquot, and so on, successively until 10 aliquots were obtained.

The results of Figure 5 shows that the foam functionalized with thioglycol presented an $11 \%$ reduction in PCBs, compared to the initial value of $65 \mathrm{mg} \cdot \mathrm{kg}^{-1}$ of the insulating mineral oil.

$50 \mathrm{~mL}$ of insulating oil ( $65 \mathrm{mg} \cdot \mathrm{kg}^{-1}$ of PCBs) were eluted at $40^{\circ} \mathrm{C}$ through $0.1 \mathrm{~g}$ (Figure 6) and $2 \mathrm{~g}$ of " $2 \mathrm{~S}$ " (non-functionalized) foam (Figure 7) were then eluted an aliquot of $2 \mathrm{~mL}$ was separated for further chromatographic analysis. The whole oil was eluted again by separating a new aliquot, and so, successively until 10 aliquots.

The previous results (Figure 6 and Figure 7) showed that the used masses of $0.1 \mathrm{~g}$ and $2.0 \mathrm{~g}$ foam presented adsorption values of PCBs very close to $29 \mathrm{mg} \cdot \mathrm{kg}^{-1}$, evidencing the high adsorption capacity of the foam functionalized even in smaller amounts of mass.

Figure 8 shows all the saturation curves of the foams containing thiodiglycol, ammonium polysulfide and nonfunctionalized foam at $40^{\circ} \mathrm{C}$ for a better evaluation.

The results shown in Figure 8 of the amounts of non-adsorbed PCBs after 10 


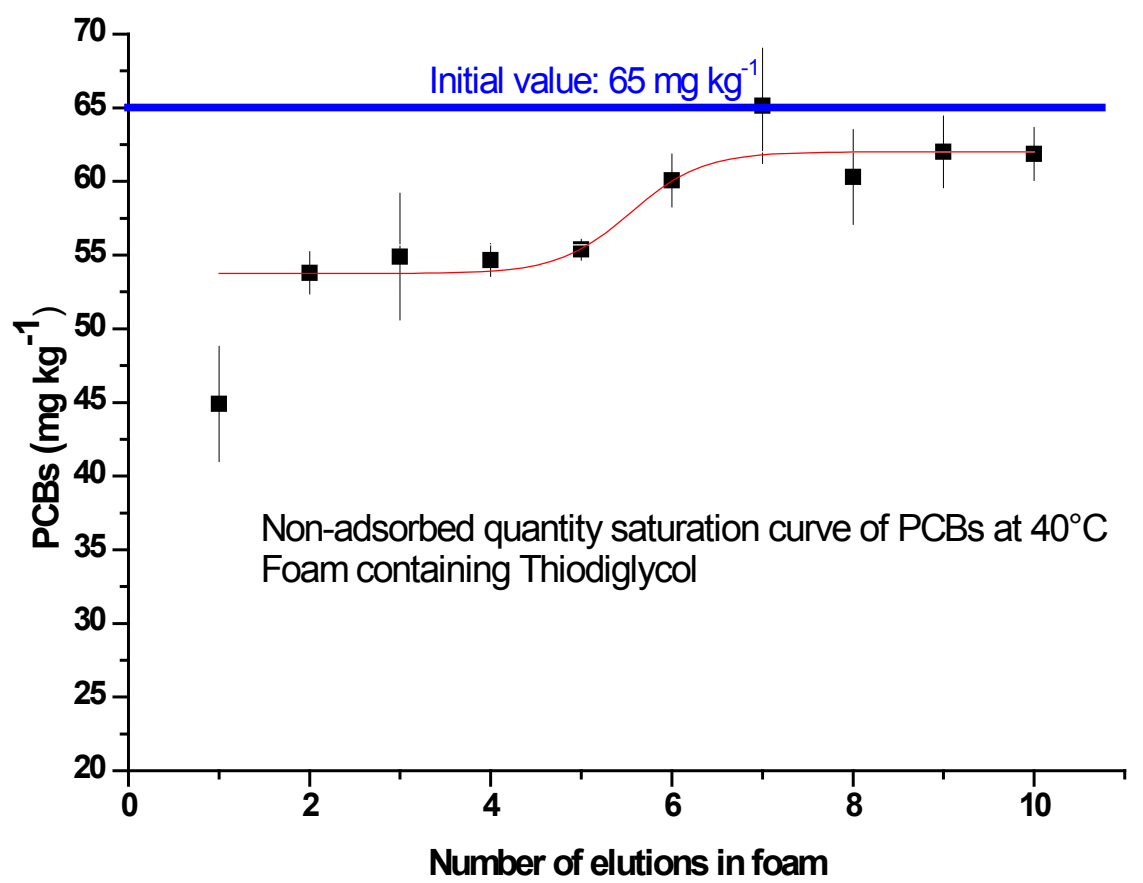

Figure 5. Non-adsorbed quantity saturation curve of PCBs at $40^{\circ} \mathrm{C}$ of $10 \%$ Tiodiglycol-functionalized foam after 10 elutions with insulating mineral oil containing 65 $\mathrm{mg} \cdot \mathrm{kg}^{-1}$ of PCBs.

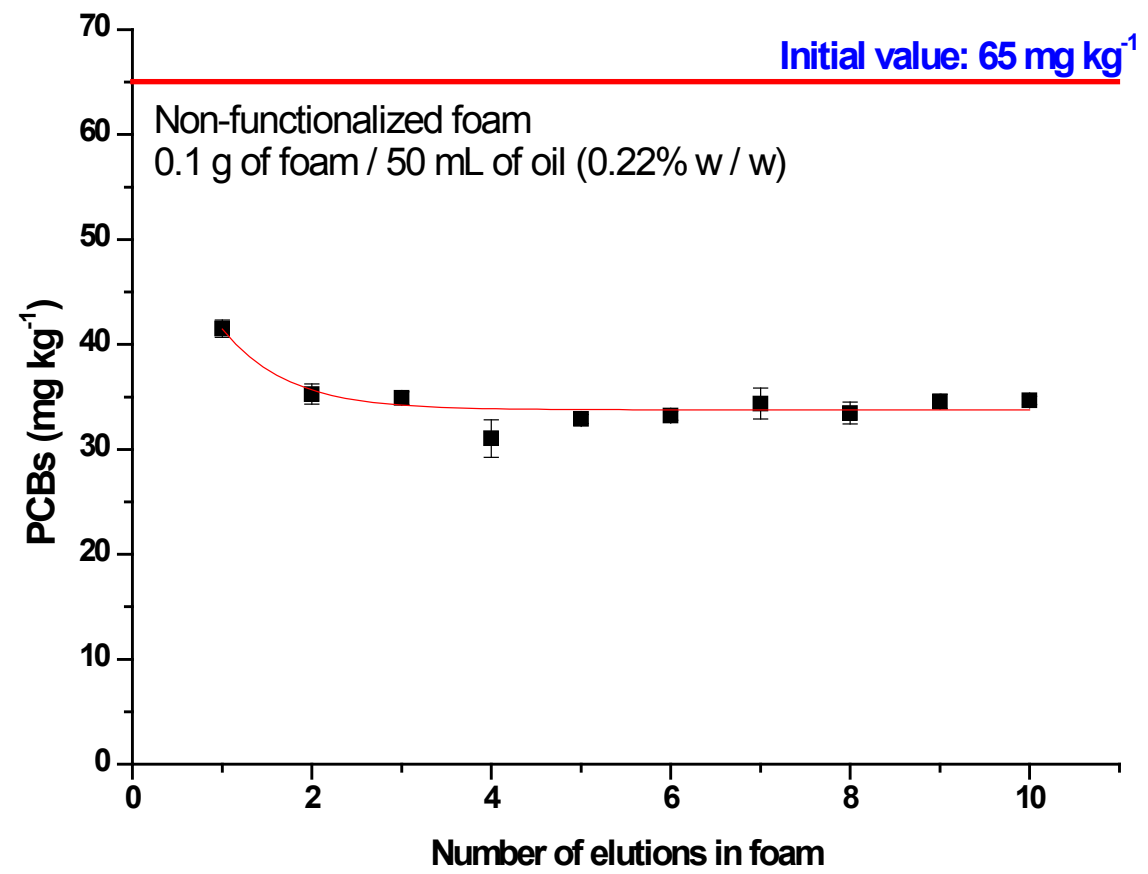

Figure 6. Non-adsorbed amount saturation curve of PCBs at $40^{\circ} \mathrm{C}$ in non-functionalized foam $(0.1 \mathrm{~g})$ after 10 elutions with insulating mineral oil containing $65 \mathrm{mg} \cdot \mathrm{kg}^{-1}$ of PCBs.

elutions suggest that when using the functionalized foam with thiodiglycol and ammonium polysulfide, there is a marked increase in PCB adsorption by the foam only at the beginning of the process. After this adsorption is decreased, 


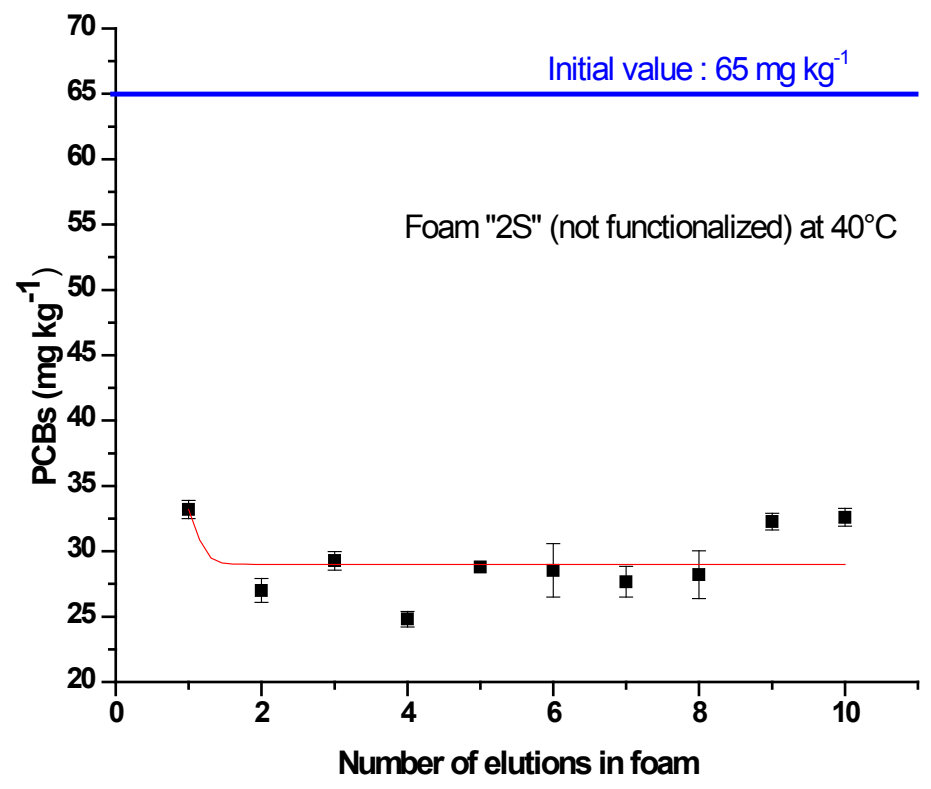

Figure 7. Non-functionalized foam saturation curve $(2 \mathrm{~g})$ for the adsorption of PCBs of the insulating mineral oil containing $65 \mathrm{mg} \cdot \mathrm{kg}^{-1}$ of PCBs at $40^{\circ} \mathrm{C}$.

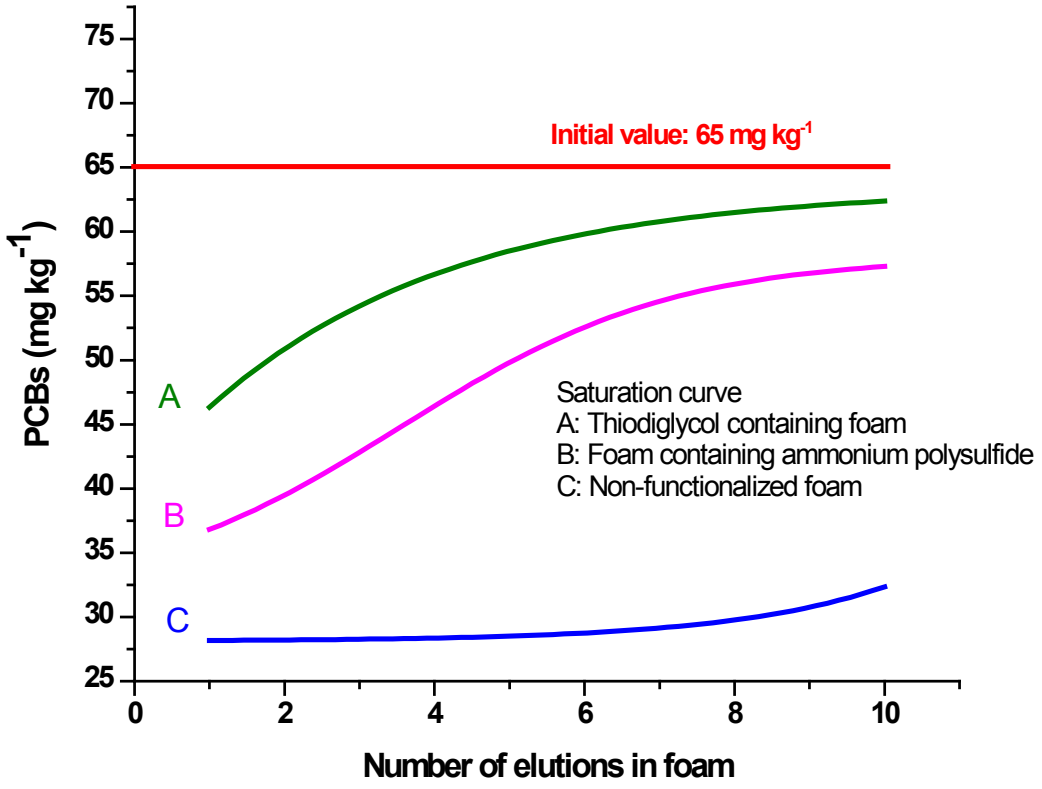

Figure 8. Saturation curve (non-adsorbed amount of PCBs starting from insulating mineral oil with $65 \mathrm{mg} \cdot \mathrm{kg}^{-1}$ of PCBs) with the foams: (A) functionalized with thiodiglycol (B) functionalized with ammonium polysulfide and (C) foam not functionalized for the adsorption of PCBs at $40^{\circ} \mathrm{C}$ after 10 elutions.

indicating that there may be some competition from the solute (PCBs) to reach the active centers of the surface (triglyceride of the ricinoleic acid present in the foam) it is well evident that the nonfunctionalized foam adsorbed a larger amount of PCBs, result shows a smaller amount of it after the elutions.

The results of Figure 9 show the saturation curves showing how much PCBs were not adsorbed on the non-functionalized foam at temperatures of $20^{\circ} \mathrm{C}$, 
$40^{\circ} \mathrm{C}$ and $60^{\circ} \mathrm{C}$ after 10 elutions and the aliquots subsequently analyzed by chromatography.

The results presented in Figure 9 with the non-functionalized foam showed a reduction of $55 \%$ of the contents of PCBs $65 \mathrm{mg} \cdot \mathrm{kg}^{-1}$ contained in the insulating mineral oil at $40^{\circ} \mathrm{C}$ in relation to the initial value, since the amount of PCBs adsorbed by the foam was lower at $40^{\circ} \mathrm{C}$, the adsorption was monitored by gas chromatography (GC-DCE), using a chromatographic column RTX5MS (5\% Diphenyl, 95\% Dimethylpolysiloxane). In the experiments, a high selectivity of polyurethane foam was observed, leading to a $55 \%$ reduction in polychlorinated biphenyls in non-functionalized foam, $24 \%$ in ammonium polysulphide functionalized foam and $11 \%$ in thiodiglycol functionalised foam. Therefore, there is a feasible formation between the donor-acceptor or the "charge transfer" systems between the several complexes of organic compounds and polychlorinated biphenyls (PCBs), postulated by several authors [9]. In addition to that the solute can establish connections with the functional groups of the solid surface by electrostatic, van der Waals or chemical attractions, all of them originating in electromagnetic interactions of the nucleus with the electrons [8].

In Figure 10 the results of the passage of a new PCB-free insulation mineral oil into the foam containing adsorbed PCBs are shown, in order to verify if there was desorption of the PCBs contained in the foam, a new mineral insulation oil, manufactured by NYNAS (Sweden), supplied by ABB-Asea Brown Boveri (Guarulhos-SP, Brazil).

The results of Figure 10 show no change in the values of PCBs obtained, PCBs obtained, which means that the oil did not extract the adsorbed PCBs in the foam showing a large adsorption and another eluent was necessary for a possible extraction. In Figure 11 the results are presented using n-hexane as

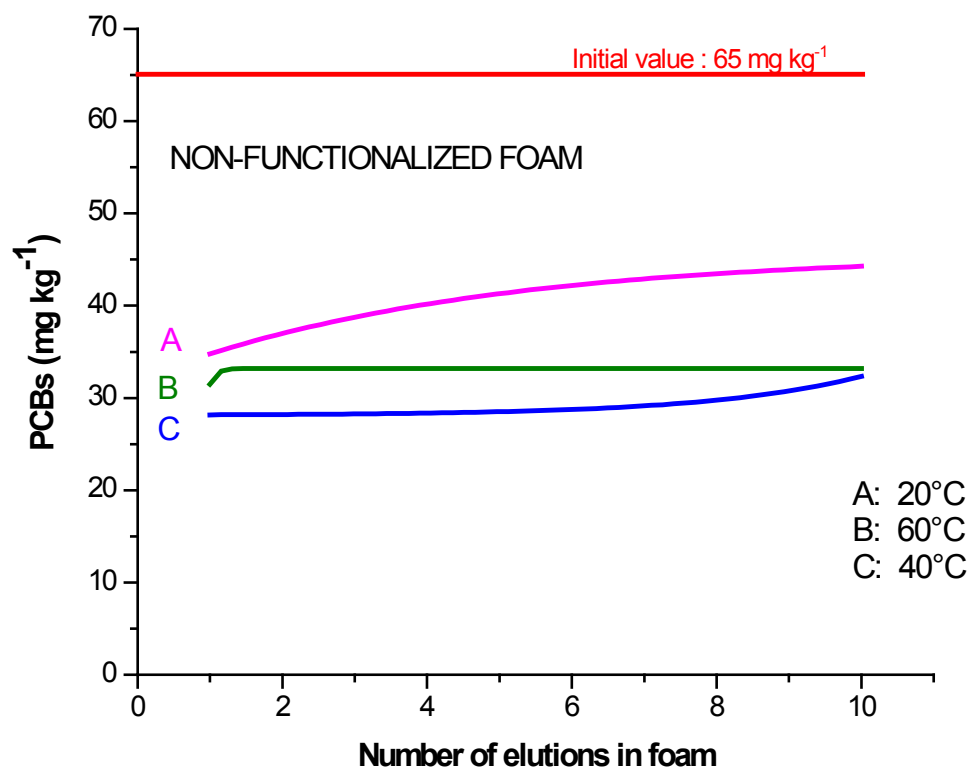

Figure 9. Non-functionalized foam saturation curve (amount of non-adsorbed PCBs) of the insulating mineral oil containing $65 \mathrm{mg} \cdot \mathrm{kg}^{-1}$ at $20^{\circ} \mathrm{C}, 40^{\circ} \mathrm{C}$ and $60^{\circ} \mathrm{C}$. 


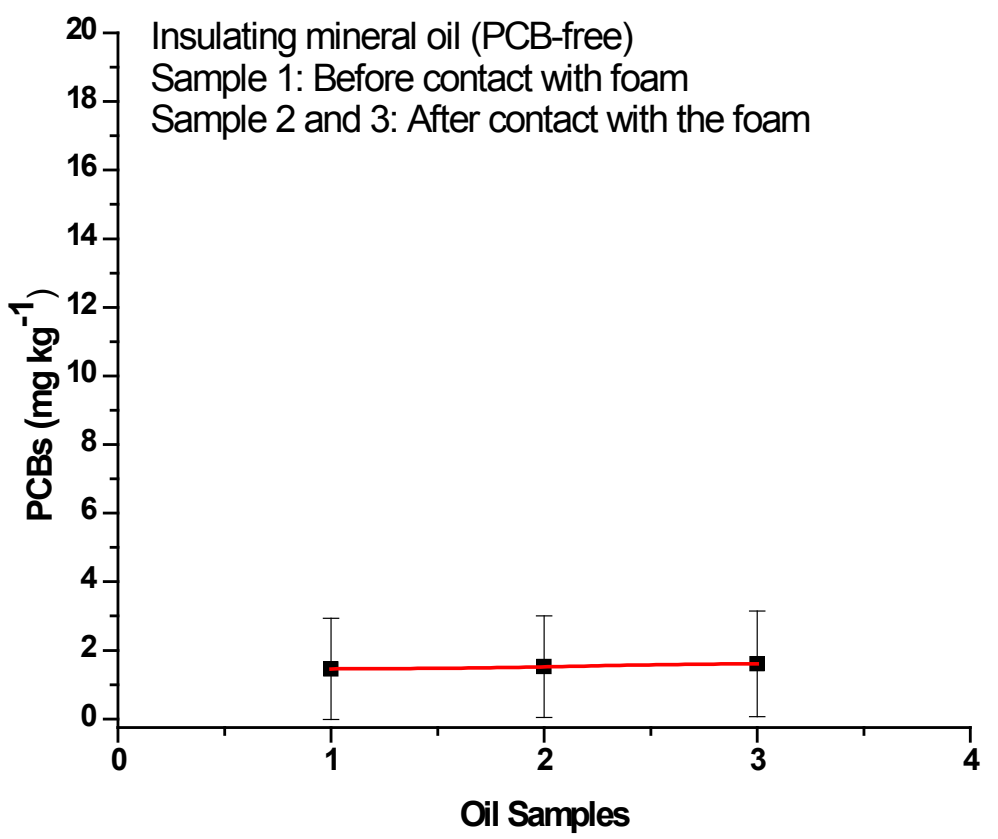

Figure 10. New insulation mineral oil, free of PCBs, before contact and after contact with non-functionalized foam (after reduction of 55\% in PCBs content).

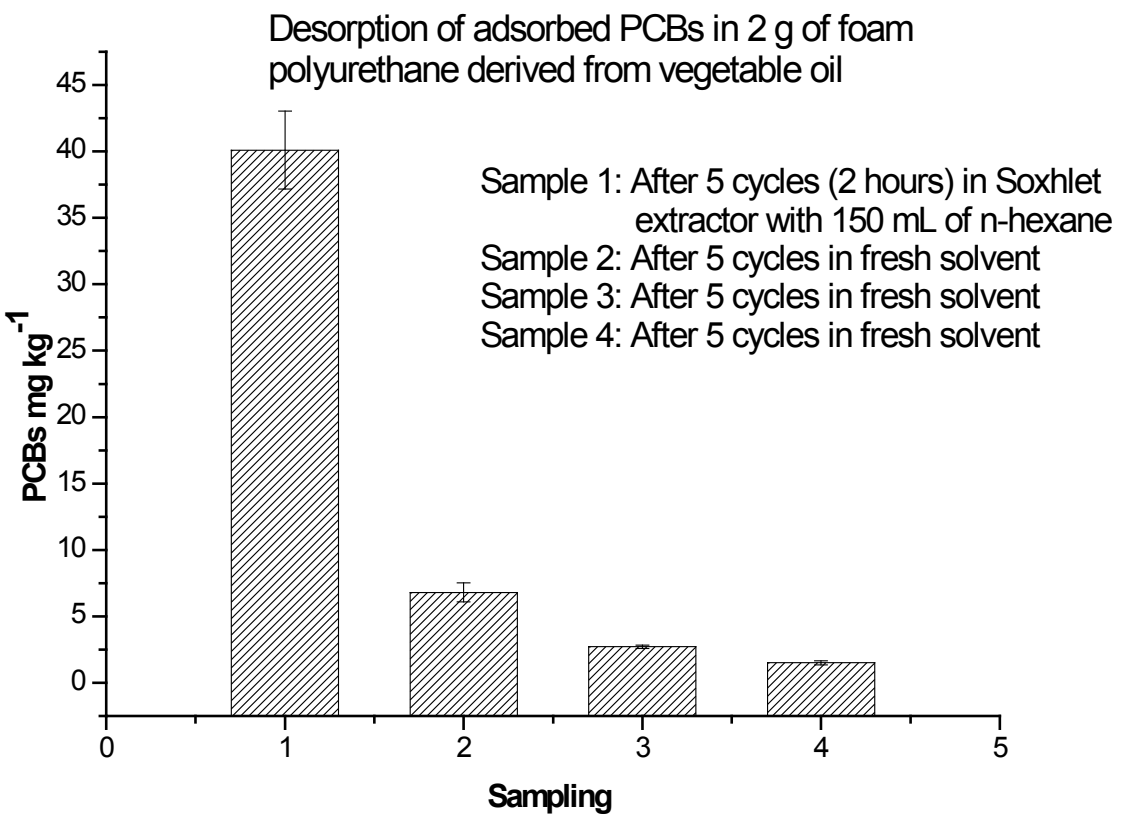

Figure 11. Desorption of adsorbed PCBs in $2 \mathrm{~g}$ non-functionalized polyurethane foam derived from vegetable oil.

solvent in the desorption of PCBs adsorbed on non-functionalized polyurethane foam at $40^{\circ} \mathrm{C}$, that temperature was used because of better adsorption. The PCB values were obtained after five cycles of solvent extraction until removal of the PCBs, every five cycles of approximately 2 hours in a total of 8 hours the solvent was replaced until the PCBs value did not vary further, within the chromatographic error. 
The extraction results of PCBs adsorbed onto the foam using the n-hexane solvent, shown in Figure 11, presented values of approximately $40 \mathrm{mg} \cdot \mathrm{kg}^{-1}$ (first cycle) to about $2.0 \mathrm{mg} \cdot \mathrm{kg}^{-1}$ (last cycle ), a $95 \%$ reduction after 4 extractions in Sohxlet extractor, changing the solvent every 5 cycles. It was monitored by gas chromatography. These results show that this polymer can be used for the extraction of mineral insulating oils contaminated with PCBs and these can be eluted with solvent $\mathrm{n}$-hexane, thus avoiding contamination of the environment. CANGEMI et al., [10] and CLARO NETO et al. [11] showed in their studies that foams synthesized from vegetable oil presented biodegradable characteristics, thus avoiding pollution of the environment.

\section{Conclusions}

The adsorption of polychlorinated biphenyls (PCBs) in mineral insulating oil was studied in a thermostatic glass column containing foam disc and pulverized rigid polyurethane foam derived from vegetable oil.

Analyzing the results of these experiments it was verified that the objective of the research was reached, since the reduction of the initial content of $65 \mathrm{mg} \cdot \mathrm{kg}^{-1}$ of PCBs contained in the oil to $29 \mathrm{mg} \cdot \mathrm{kg}^{-1}$ presented a reduction of $55 \%$ above the specified minimum value of $50 \mathrm{mg} \cdot \mathrm{kg}^{-1}$. Therefore, this research reached the proposed objective for the reuse of the insulating mineral oils subjected to this adsorption and desorption process aiming at decontamination, minimization of costs and environmental impacts.

\section{Acknowledgements}

Our sincere thanks to CAPES, CNPq and FAPEMIG for financial support.

\section{Conflicts of Interest}

The authors declare no conflicts of interest regarding the publication of this paper.

\section{References}

[1] Appelt, D. (1975) Óleos Isolantes Para Transformadores. Eletricidade, 113, 60-73. http://www.colecoesfundacaoedp.edp.pt/Nyron/Library/catalog/winlibsrch.aspx?ske $\mathrm{y}=\mathrm{D} 65 \mathrm{E} 6 \mathrm{AC} 255 \mathrm{~F} 849 \mathrm{~B} 1 \mathrm{~B} 6 \mathrm{EC} 6 \mathrm{E} 6 \mathrm{CF} 1702 \mathrm{E} 40$ \&pesq=3\&cap=\&var1=dietmar\&var2 = \&var12=\&doc $=164924$

[2] Penteado, J.C.P. and Vaz, J.M. (2001) The Legacy of the Polychlorinated Biphenyls (PCBs). Química Nova, 24, 390-398.

http://www.scielo.br/scielo.php?script=sci_arttext\&pid=S0100-40422001000300016

[3] Associação Brasileira de Normas Técnicas (2013) NBR 13882:2008, Líquidos Isolantes Elétricos-Determinação do Teor de Bifenilas Policloradas. Rio de Janeiro.

[4] Associação Brasileira de Normas Técnicas (2005) NBR 8371, Ascarel para transformadores e capacitores-Características e riscos. Rio de Janeiro.

[5] Associação Brasileira de Normas Técnicas (2013) NBR 8840, Óleo mineral isolante de equipamentos elétricos-Diretrizes para amostragem de líquidos isolantes. Rio 
de Janeiro.

[6] Bellar, T.A. and Lichtenberg, J.J. (1975) Some Factors Affecting the Recovery of Polychlorinated Biphenyls (PCB's) from Water and Bottom Samples. In: ASTM, Ed., American Society for Testing and Materials, Philadelphia, 206-219.

[7] Weber Junior, W.J. (1972) Physicochemical Processes: for Water Quality Control. 1st Edition, Wiley-Interscience, New York.

[8] Voice, T.C. and Weber Junior, W.J. (1983) Sorption of Hydrophobic Compounds by Sediments, Soils and Suspended Solids-I: Theory and Background. Water Research, 17, 1433-1441. https://doi.org/10.1016/0043-1354(83)90275-0

[9] Senesi, N. and Testini, C. (1983) Adsorption of Some Nitrogenated Herbicides by Soil Humic Acids. Ecological Bulletins, 35, 477-490.

[10] Cangemi, J.M., Claro Neto, S., Chierice, G.O. and Santos, A.M. (2006) Study of Biodegration of a Polymer Derived from Castor Oil by Scanning Electron Microscopy, Thermogravimetry and Infrared Spectroscopy. Polimeros e Tecnologia, 16, 129-136.

[11] Claro Neto, S., Santos, A.M. and Chierice, G.O. (2014) Avaliação da biodegradação de poliuretano de óleo vegetal com excesso de isocianato. Brazilian Journal of Thermal Analysis, 3, 1-4.

[12] Camargo (2010) Marcio Antonio Ferreira. Espumas poliuretânicas derivadas de óleo de mamona utilizadas na adsorção de bifenilas policloradas (PCBs) presentes em óleo mineral isolante. Tese (Doutorado em Química Analítica)-Instituto de Química de São Carlos, Universidade de São Paulo, São Carlos. 